\title{
Advanced Stage Primary Lung Cancer Masquerading as Empyema in a 23-Year-Old Male
}

\section{Sando S, Ramirez A and Lazar JF*}

Pinnacle Health Robotics Institute, Harrisburg, PA, USA

\begin{abstract}
Lung cancer continues to be the number one cancer killer among men and women in the United States. Smoking stands as the primary risk factor for developing lung cancer. Consequently, primary lung cancer may act differently in young adults than expected in older adults. Many young adults diagnosed with lung cancer are never smokers and otherwise healthy. Genetic driver mutations are often found in these young adults and targeted therapy is initiated. We present a case of a 23-year-old intravenous drug user found to have advanced stage lung cancer during work up of an apparent empyema.
\end{abstract}

Keywords: Empyema; Masquerading; Hemoptysis; Drug abuse

\section{Introduction}

Diagnosing a primary lung cancer in a young adult is very rare with a range of $0.4 \%$ to $14 \%$ in retrospective studies with at least 100 patients $[1,2]$. Most studies in patients in their twenties are limited to a handful of case reports [3-5]. Presenting symptoms are commonly weight loss, hemoptysis, pain, or respiratory complaints. Most often, these symptoms occur when the cancer has reached an advanced stage. On the contrary, infectious complications in an intravenous drug user are very common. We present a case of a 23 -year-old intravenous drug user found to have advanced stage lung cancer during work up of an apparent empyema.

\section{Case Report}

A 23-year-old white male with a history of migraine headaches and intravenous drug abuse on methadone presented with worsening shortness of breath, fatigue and productive cough. He smoked one pack of cigarettes per day for the past five years. Initial laboratory evaluation was unremarkable; however, chest radiograph revealed a large right sided pleural effusion (Figure 1). A Computed Tomography (CT) chest confirmed a large right pleural effusion and subsequently treated with a pigtail catheter that was ultimately determined to be exudative. With cultures pending, the patient was treated prophylactically on intravenous antibiotics. Without complete expansion of the right lower lobe, the patient was taken for right Video Assisted Thoracoscopic Surgery (VATS) with the plan to decorticate the lung. The lower and middle lobes were grossly adhered with loculations. Visually they appeared abnormal and felt too dense for an abscess. Consequently, multiple biopsies were taken from the pleura and surrounding tissues. Cytology examination revealed atypical cells. Pathology from pleural biopsies was positive for non-small cell lung cancer-favor adenocarcinoma with cytokeratin 7 and TTF-1 positive and cytokeratin 20, CDX-2, CD30, PLAP and glypican 3 negative. Given ongoing high chest tube output, an indwelling tunneled pleural catheter was placed. All antibiotics were stopped and a PET scan obtained as an outpatient showed significant uptake in the right chest with skeletal metastasis (Figure 2). Medical Oncology began him on an oral kinase inhibitor after genetic testing was positive for an ALK driver mutation. The tunneled pleural catheter was removed three months later after an auto pleurodesis effect.

\section{Discussion and Conclusion}

Of the estimated 222,500 new cases of lung cancer diagnosed each year, less than $2 \%$ are in patients younger than 45 years old. The risk

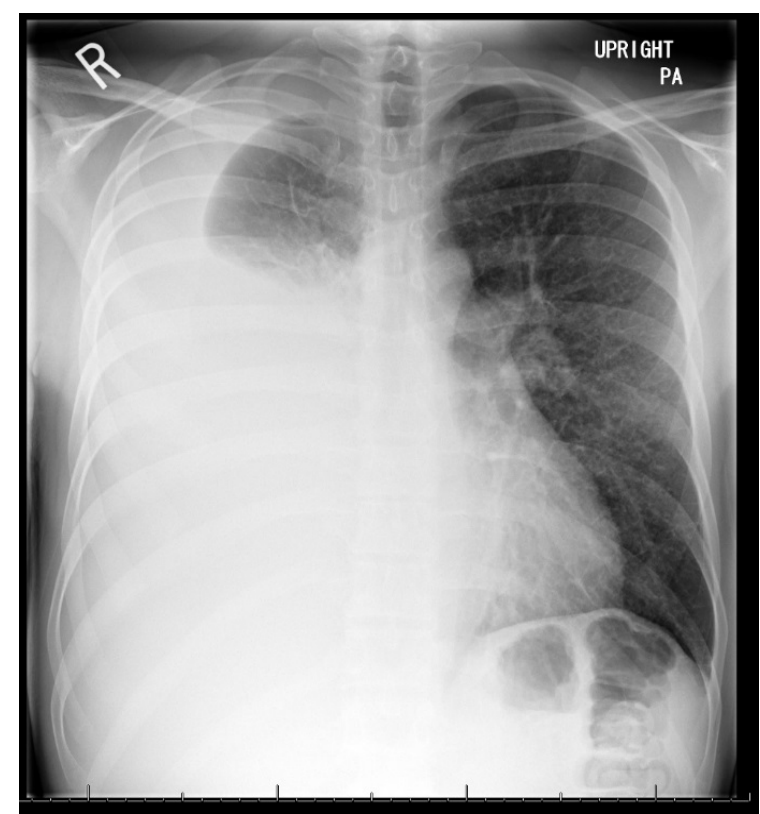

Figure 1: Chest radiograph upon initial presentation with near complete right sided opacification.

of a cancer diagnosis increases in accordance with a patient's age, with the average age at diagnosis about 70 [6]. Broken down even further by the Surveillance, Epidemiology, and End Results Program (SEER) by the National Cancer Institute for patient age range 20-24, as our case subject, the incidence of non-small cell lung cancer is 0.3 per 100,000 . While lung cancer generally afflicts men at a higher incidence than women, this is not true in young adults, with no significant differences between sexes until over the age of 50 [7]. The rarity of lung cancer increases as the age decreases.

*Corresponding author: Lazar JF, Pinnacle Health Robotics Institute, Harrisburg PA, USA, Tel: +1 717-988-5864; E-mail: jflazar@me.com

Received May 03, 2017; Accepted May 11, 2017; Published May 20, 2017

Citation: Sando S, Ramirez A, Lazar JF (2017) Advanced Stage Primary Lung Cancer Masquerading as Empyema in a 23-Year-Old Male. Lung Dis Treat 3: 122. doi:10.4172/2472-1018.1000122

Copyright: @ 2017 Sando S, et al. This is an open-access article distributed under the terms of the Creative Commons Attribution License, which permits unrestricted use, distribution, and reproduction in any medium, provided the original author and source are credited. 


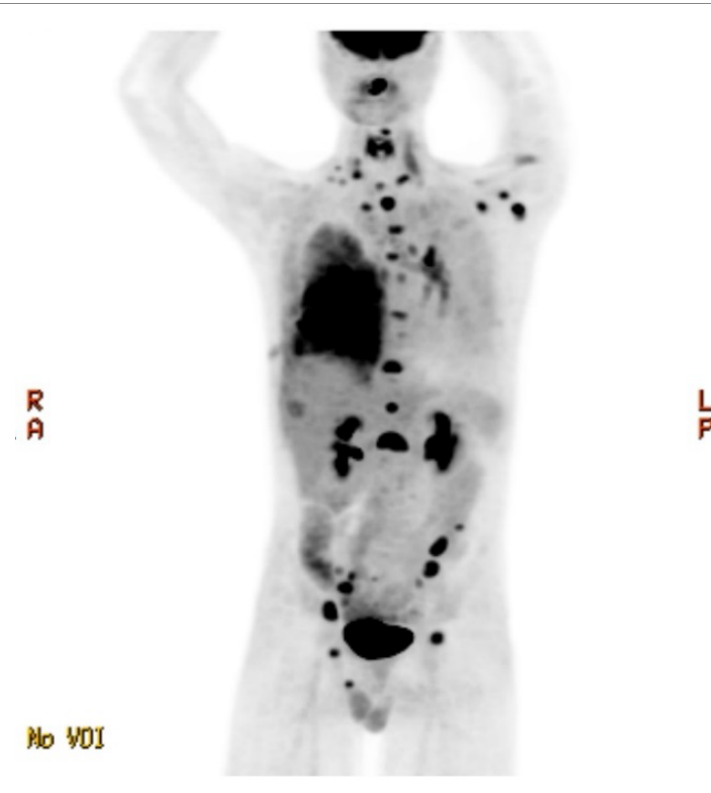

Figure 2: Maximum intensity projection from PET/CT scan showing large right avid mass with significant lymph node uptake and numerous boney metastases.

The most influential factor in inducing cancer susceptibility is smoking. Genetic studies have shown the TP53 mutation at the molecular level is most heavily associated with smoking [8]. Similarly to the incidence of lung cancer between sexes, lung cancer in young adults is not directly related to smoking-with many being athletic, never smokers. While research is scarce, preliminary results from the Genomics of Young Lung Cancer Study have identified genetic mutations that are able to pinpoint the genomic location of specific lung cancer subtypes. It is through this identity that a more accelerated delivery of treatment has the greatest therapeutic effect [9].

Contrary to the rarity of lung cancer in a young adult, there is an estimated 19.5 million Americans (8.2\% of the population) who have used an illicit drug in the past month. The culmination of poor hygiene, a weakened immune system, improper needle use, the use of non-sterile needles, and the sharing of drug paraphernalia leads to high infection rates among intravenous drug users. Respiratory tract infections are among the most common and typically present with abnormal radiographic findings [10].

Our subject presented with abnormal radiologic findings and associated respiratory complaints. With previous intravenous drug abuse and the commonality of infection in this population, a parapneumonic effusion/empyema was assumed. A far more menacing diagnosis was quickly realized and acting upon by the team, but altogether unexpected given a patient of this age.

\section{References}

1. Rich AL, Khakwani A, Free CM, Tata LJ, Stanley RA, et al. (2015) Non-small cell lung cancer in young adults: presentation and survival in the English National Lung Cancer Audit. QJM 108: 891-897.

2. Radzikowska E, Roszkowski K, Glaz $P$ (2001) Lung cancer in patients under 50 years old. Lung Cancer 33: 203-211.

3. Emori Y, Kiura K, Yoshino T, Notohara K, Tsuchida T, et al. (1999) Very young patient with peculiar squamous cell carcinoma of the lung. Intern Med 38: 979-983.

4. Katsuragi N, Shiraishi $\mathrm{Y}$, Kita $\mathrm{H}$ (2007) 21-year-old man with squamous cell carcinoma of the lung. Kyobu Geka 60: 529-532.

5. Tajiri T, Suita S, Shono K (1999) Lung cancer in a child with a substantial family history of cancer. Eur J Pediatr Surg 9: 409-412.

6. https://www.cancer.org/cancer/non-small-cell-lung-cancer/about/key-statistics.html

7. https://seer.cancer.gov/

8. Brennan P, Hainaut P, Boffetta P (2011) Genetics of Lung Cancer Susceptibility. Lancet Oncol 12: 399-408.

9. Gitlitz BJ, Morosini D, Sable-Hunt AL, Addario BJ, Jennings MB, et al. (2014) The genomics of young lung cancer study. J Clin Oncol.

10. Rachel GJ, Lowy FD (2005) Bacterial infections in drug users. NEJM 353 1945-1954. 